\title{
Plastic pollution challenges in marine and coastal environments: from local to global governance
}

\author{
Joanna Vince ${ }^{1,2,3}$, Britta Denise Hardesty ${ }^{4}$
}

Plastic pollution in the marine and coastal environment is a challenging restoration and governance issue. Similar to many environmental problems, marine plastic pollution is transboundary and therefore the governance solutions are complex. Although the marine environment is unlikely to return to the condition it was in before the "plastic era," it is an example of an environmental restoration challenge where successful governance and environmental stewardship would likely result in a healthier global oceanic ecosystem. We argue that a holistic, integrated approach that utilizes scientific expertise, community participation, and market-based strategies is needed to significantly reduce the global plastic pollution problem.

Key words: community engagement, corporate social responsibility, litter

\section{Conceptual Implications}

- To date, local, regional, and international governance has failed to stem the tide of plastic entering the marine environment.

- Global and local governance responses are needed to effectively manage the plastic marine litter problem.

- Coordinating state and nonstate efforts in a holistic, integrated way is essential to reducing and mitigating plastic marine litter.

Marine litter is as much a transboundary global problem as well as a local issue with a multitude of sources. An estimated 6-12 million tonnes of plastic enters the oceans each year (Jambeck et al. 2015). The pollution is significant and widespread, with plastic debris found on even the most remote coastal areas (STAP 2011) and in every marine habitat (do Sul \& Costa 2014). Nearly 700 marine species have been found to interact with marine debris to date (Gall \& Thompson 2015), with ingestion and entanglement the two main types of interaction (Secretariat of the Convention on Biological Diversity and the Scientific and Technical Advisory Panel, GEF 2012 [referred to here within as GEF]). We discuss many of the complexities of this environmental restoration challenge, focusing particularly on governance responses to the issue at local, regional, and international scales. We do, however, acknowledge that an in depth discussion of all critical aspects of marine litter governance is not possible here.

Although scientific studies are revealing the causes and consequences of marine plastic pollution, governments and nonstate actors are tackling solutions in myriad disparate ways. To highlight the complexities of this environmental restoration challenge, we examine current governance arrangements addressing marine litter on international and national levels. We describe market and community strategies that offer different solutions that government and international organizations are unable to provide such as education, outreach, and corporate social responsibility (CSR). We argue that combining governance solutions with scientific expertise can offer a holistic, integrated approach to reducing litter and waste entering the oceans - the first crucial step toward environmental restoration of our waterways, coastlines, and oceans. According to Underdal (1980), "To 'integrate' means to unify, to put parts together into a whole. Integrated policy, then, means a policy where the constituent elements are brought together and made subjects to a single, unifying conception." Although policy integration is complex (Howlett et al. 2015), it is recognized by the international community as the way forward for managing activities in ocean and coastal areas (e.g. through international instruments such as United Nation Conference on the Environment and Development's (UNCED) Agenda 21 (1992); United Nation Convention on the Law of the Sea (UNCLOS) (1994); and the World Summit on Sustainable Development (2002)).

Litter found in the coastal and marine environment ranges from macrodebris such as large industrial containers, plastic bags, drink containers, cigarette butts, and plastic fragments, to small microdebris including manufactured plastic pellets and microbeads from consumer items. This anthropogenic litter, comprised mostly of plastic, interacts not only with marine megafauna such as seabirds, turtles, marine mammals, and fish but also with bivalves, lugworms, oysters, and corals.

Author contributions: JV, BDH conceived of, designed the research, and wrote the article.

${ }^{1}$ Politics and International Relations Program, School of Social Sciences, University of Tasmania, Locked Bag 1340, Launceston, Tasmania 7250, Australia

${ }^{2}$ Centre for Marine Socio-ecology, University of Tasmania, Hobart, Tasmania 7001, Australia

${ }^{3}$ Address correspondence to J. Vince, email Joanna.vince@utas.edu.au

${ }^{4}$ CSIRO Oceans and Atmosphere, GPO Box 1538, Hobart, Tasmania 7000, Australia

(C) 2016 Society for Ecological Restoration

doi: $10.1111 /$ rec. 12388 
Although the demonstrated impacts to wildlife are most frequently reported at the organismal and suborganismal levels (Rochman et al. 2015), experts view entanglement, ingestion, and chemical contamination as all having the potential for significant (lethal or sublethal) impacts to major marine vertebrates (Wilcox et al. 2016).

Microplastics are a specifically identified subset of marine pollution that is of particular concern. Defined as particles $\leq 5 \mathrm{~mm}$ in size (Masura et al. 2015), microplastics result both from the breakdown of larger plastics and through manufacture specifically for use in consumer goods. Indeed, the prevalence of marine plastic pollution and its impacts on coastal economies, marine ecosystems, and human health demonstrates that there are no simple solutions to this environmental restoration challenge.

\section{Global Governance}

There is a large gap in international hard law specifically addressing land-based plastic marine pollution. UNCLOS Part XII (articles 192-237) is dedicated to the protection and preservation of the marine environment. Although UNCLOS recognizes that there are six different sources of marine pollution, including land-based, it does not go into detail about the type of pollutants and technical rules (Palassis 2011). States are directed to adopt their own laws and regulations addressing marine pollution and to work with the International Maritime Organisation (IMO) in the establishment of rules regarding ship-sourced pollution.

The IMO has negotiated a number of international instruments to address state, ship, and port responsibilities. The 1972 Convention on the Prevention of Marine Pollution by Dumping of Wastes and Other Matter (London Dumping Convention) was designed to promote effective control over all sources of pollution affecting the marine environment. It also listed the substances that could or could not be dumped at sea. However, it is not self-regulating and needs contracting parties to implement national legislation for enforcement. The 1973 International Convention for the Prevention of Pollution from Ships (MARPOL) and the 1978 Protocol to MARPOL addresses the gaps of the London Dumping Convention. Annex V of MARPOL, entered in 1998, was revised in 2011 and entered into force in 2013. This annex is particularly important with regard to marine litter as it explicitly prohibits the disposal of plastics anywhere at sea. However, compliance remains an issue and states are in varying phases of implementing their domestic policies accordingly.

Plastic pollution is a global issue, and when it occurs in Areas Beyond National Jurisdiction (ABNJ) the issue of responsibility is particularly problematic. For example, the well-known "Pacific Garbage Patch" is one of five accumulation regions for marine debris. It is located in the east and west parts of the Pacific (Kaiser 2010; Titmus \& Hyrenbach 2011). Finding solutions to removing debris far from land or taking responsibility for it within $\mathrm{ABNJ}$ from a governance and practical perspective is complex. Market-based solutions have been suggested to clean up this "garbage patch"; however, the legal parameters on the high seas are limited to UNCLOS, demonstrating the gap in international law when it comes to the mitigation and removal of marine debris from ABNJ.

Generally speaking, soft law dominates global efforts to address marine debris and is an essential part of the existing regime. For instance, UNCED's Agenda 21 encourages integrated, precautionary, and anticipatory marine environmental protection (UNCED 1992). Chapter 17 sets out precautionary measures to addressing marine debris such as recycling, sewerage treatment facilities, and environmental impact assessments. It also outlines the actions required for the prevention, reduction, and control of ship-sourced pollution (Palassis 2011).

The Conference of the Parties to the CBD (COP CBD) Scientific and Technical Advisory Panel of the Global Environment Facility released a report on the impacts of marine debris on marine and coastal biodiversity in 2012 (GEF 2012). A decision to address the impacts of marine debris on marine and coastal biodiversity was adopted through Decision XI/18 at the 11th Meeting of COP CBD.

Furthermore, The United Nations Environment Program (UNEP) has released specific guidelines for addressing marine pollution (UNEP 2009a). In 2012, The Honolulu Strategy (UNEP 2012) was released and was adopted by participants of a global marine debris conference and represents a global strategy to reduce marine debris. Also that year, the UNEP Global Partnership of Marine Litter (GPML) was announced. It is the coordinating forum for stakeholders at all levels working on marine debris prevention and management (also see UNEP 2009b).

\section{National and Subnational Governance}

Many countries are taking national approaches to addressing marine debris through legislation, policies, and action plans. In Australia, the Environment Protection and Biodiversity Conservation $(E P B C)$ Act 1999 lists threatened marine species that are affected by marine debris. In 2009, the Threat Abatement Plan for the Impacts of Marine Debris on Vertebrate Marine Life was released. The plan's objectives aimed to find a decline in the extent of marine debris in the Australian environment and in the number of vertebrates affected by marine debris. The plan is currently under revision and the Australian Senate has launched an inquiry into marine plastic pollution to be completed in 2016.

The United States has enacted the Marine Debris Research, Prevention and Reduction Act (2006) which was amended in 2012 (Marine Debris Act Amendments). A National Marine Debris Program was established as a result of the Act and this national program supports research, outreach, education, and provides monitoring guidelines for marine litter (Opfer et al. 2012). Individual states have also taken action on particular components of marine debris, with recent interest in reducing microbeads in consumer products. In 2015, the California Assembly voted to prohibit the sale of microbeads in personal 
care products from 2020. California's actions with regard to marine debris are significant, and already the impact of the "California effect" (Fredriksson \& Millimet 2002; Perkins \& Neumayer 2012) is being seen elsewhere. Other jurisdictions including Washington State and Maryland are passing similar legislation. In Canada, a formal request to the Canadian government from key nongovernmental organisations (NGOs) asked for microbeads to be placed on the Priority Substances List so that they can be regulated as toxic substances under the Canadian Environmental Protection Act (Ecojustice 2015). If passed, this will not only be a regulatory issue but one that will affect market and consumer actions.

\section{Community and Civil Society Approaches}

Bottom-up, community governance solutions to reducing marine pollution can have substantial impact. For example, GhostNets Australia (GNA) works with an alliance of indigenous communities from Northern Australia who remove fishing gear from coastal Australia. Since 2004, indigenous rangers have removed more than 13,000 derelict fishing nets and rescued 400 turtles as part of on-ground activities (Ghostnets Australia 2015). With GNA and ranger-collected data, areas of greatest impact on turtles, cost-effective areas to remove nets, nets having the greatest impact on marine turtles, and regions for net interdiction have been identified (Wilcox et al. 2013, 2014, 2016).

Education and outreach also increases awareness and understanding of marine debris impacts (Derraik 2002). In Australia, the TeachWild program was a national partnership project with the Commonwealth Scientific and Industrial Research Organization (CSIRO), Earthwatch, and Shell Australia. The program "engages students in citizen science, including scientific methodology, data collection and analysis of marine debris" (Department of the Environment 2015) and data collected from the project is uploaded into the Australian National Marine Debris database. This is an interesting example of CSR for Shell Australia, actively supporting education, community engagement, and awareness-raising of plastic marine debris. The program also supports tracking debris through citizen science (Jambeck \& Johnsen 2015). Increasing engagement between community and scientists can filter through to a broader demographic and result in behavioral change around the use and removal of plastics from the marine and coastal environment.

NGOs are also influential actors within community governance. While larger NGOs such as Greenpeace, World Wildlife Fund, and World Conservation Union address marine litter within their oceans programs/portfolios, other NGOs are issue-specific. For example, Beat the Microbead is an international campaign that reports which products do or do not contain microbeads and is accessible through their website or phone "app" (Beat the Microbead 2015).

The multitude of community or "bottom-up" approaches to tackling marine litter-related issues and governance point to the complexity of the issue. Different actors target different groups, speak with different voices, and employ different methods, resources, and ideologies in their pursuit to combat various aspects of the marine litter issue. The influence of community-based groups or NGOs is varied and can result in significant change to government regulations and industry policy (e.g. microbead bans have been enacted or are under consideration in several states and countries).

\section{Market-Based and Entrepreneurial Approaches}

In addition to community approaches, market-based governance approaches address plastic marine debris in two ways. First, there are the direct economic costs of the pollution and its removal (McIlgorm et al. 2011; Newman et al. 2015). Second, participants in the market engage in CSR and actively participate in reducing or removing plastic marine debris. UNEP identifies market-based instruments such as taxes, charges, fees, fines, and penalties (UNEP 2009c). The basic principles behind these instruments include polluter pays, user pays, and full cost recovery. Market-based instruments such as container deposit schemes in Australia and the United States (Hardesty et al. 2014), cash for containers in Germany, or cash back for nets in Korea (Cho 2009) have been used effectively to reduce littering and marine debris.

CSR is an important priority for some companies involved in the development, distribution, and life cycle of consumer products plastics. According to a report by the Secretariat of the Convention on Biological Diversity and the Scientific and Technical Advisory Panel, "many companies now see packaging and plastics sustainability as part of broader CSR, and negative brand image is becoming a major driving force which is being harnessed in the interests of improving packaging materials and technologies" (GEF 2012, p 36). In 2011, industry plastics associations came together and developed a global Declaration for Solutions on Marine Litter. By December 2013, 60 associations in 34 countries had signed this Declaration (Marine Litter Solutions 2014). Although CSR can be a way for corporations to "obtain a social license to operate" (Gjølberg 2009), they are ultimately in control of their CSR policies and activities. Through social license, communities and consumers can drive changes to corporate policies and products; they can also withdraw their social license (Morrison 2014) (e.g. smoking in buildings). Alternately, some litter reduction initiatives put the responsibility on to the individual consumer to change their actions, rather than corporations (e.g. life without plastic campaign).

One example of entrepreneurial engagement is the Ocean Clean Up Project. The project aims to remove half the litter in the Pacific Garbage Patch in 10 years and sell back recovered plastics for profit (The Ocean Cleanup 2015). However, this project is highly controversial with members of the public in support (as evidenced by success in crowd-source funding exceeding US\$2 million), but the scientific community having serious concerns (Dugdale 2015). Scientists favor source-reduction and have pointed out solutions in the coastal zone would be more economical and cost-effective to reduce harm to humans and marine wildlife. 
The dynamic nature of the issue is particularly noticeable in the microbead debate. The legislative changes (see earlier) and consumer sentiment have had a significant impact on industries and the use of microbeads in personal care products. However, legislative loopholes remain for companies that may not want to change from plastic to natural alternatives (Abrams 2015). The social license for acceptable behavior regarding plastic use and disposal has been changing dramatically in recent decades and will continue to do so.

\section{Scientific Expertise}

There is no doubt that governance arrangements that address marine debris rely on scientific data and research. The expertise through an epistemic community (Haas 1992) that has evolved around the issue of marine litter and scientific knowledge provides a sound basis for agenda setting and policy formulation. Science, community, and local knowledge can guide the direction of policy responses to ecological restoration. However, as found elsewhere in oceans governance, decision makers need to understand how this knowledge works in practice and incorporate it into policy design for effective policy outcomes (Nursey-Bray et al. 2014).

Industry has called on science to drive marine litter policy and there is increasing dialogue between industry, science and NGOs (Hardesty personal observation; Toloken 2014). There is increasing scientific evidence for both the impact of marine debris on species and ecosystems (Rochman et al. 2015), and for the need to restore or reduce litter inputs to the marine environment. Researchers are asking how much litter enters or is in the ocean (e.g. Jambeck et al. 2015; van Sebille et al. 2015), about impacts on wildlife (e.g. Gall \& Thompson 2015), the effects of chemical contamination (e.g. Rochman et al. 2012) and the potential human health risk (Thompson et al. 2009).

\section{A Way Forward for Governance and Marine Ecological Restoration?}

Reducing litter inputs and impacts on marine ecosystems is the first critical step in marine environment restoration. It requires a variety of solutions at local, regional, national, and global scales. With the problem worsening, formal governance through international institutions or instruments, regional organizations or governments alone cannot resolve this exponentially increasing environmental problem. Researchers (see Chen 2015) recognize the limitations of existing international law and are calling for the development of a new international instrument specifically addressing marine debris. Although this is an important way forward, the process will be complex, may not be supported by all coastal states, and will not come into force any time soon. Both amendments to existing instruments and further implementation will need to occur on national (and international) scales to effect global change (Gold et al. 2013; Chen 2015).

Reducing marine plastic pollution nationally can occur through integrated policy approaches (Underdal 1980;
Nollkaemper 1994; Rayner \& Howlett 2009; Hu 2012). Integrated approaches have been applied to national oceans policies and marine spatial planning with varying levels of success (Jay et al. 2013; Vince 2015). Although it is recognized as one of the most difficult policy designs to implement (Howlett et al. 2015), integrated approaches provide a holistic approach to managing a problem where governments (national, state/provincial, and local), NGOs, key industries, and communities can work together. Because marine debris is a complex, pressing issue, an integrated approach would more likely be supported by political actors and the wider community.

A faster way forward can be found in bottom-up community-based approaches that filter through to formal governance structures. Changing community behavior through education has been successful (e.g. Duckett \& Repaci 2015). Also, the community as consumers can influence markets - changing the way plastics are utilized in goods that they consume. Corporate and consumer social responsibility has a large role to play in the success of measures used to address marine plastic pollution. Corporations that are proactive (rather than reactive) may gain consumer confidence in their products. CSR can also be facilitated by government regulation. This can be achieved through improved labeling, plastic bag bans, industry clean-up levies, and support for container deposit schemes. CSR will continue to drive some corporations toward changes although the challenge will be for changes to be associated with profit.

Technology and ingenuity also have a role to play, particularly where simple, cost-effective approaches to reducing litter inputs can be developed or improved. For example, synthetic aperture radar (SAR) or remote sensor cameras aboard ships of opportunity can detect large floating items in the ocean. And simple, affordable rubbish traps at river mouths are being used to remove litter before it reaches the ocean - and can have ancillary benefits such as awareness raising and community engagement (e.g. "Mr. Trash Wheel" in Baltimore, Maryland; http://baltimorewaterfront.com/healthy-harbor/water-wheel).

To be effective, litter reduction and management solutions will also require significant management of marine estates as part of restoration efforts. We recommend focusing particularly in coastal areas, as the local density of coastal and marine litter can be particularly high in urban and coastal regions (Hardesty et al. 2014), and litter removal/reduction is likely to be most effective here. Restoration of marine ecosystems is undeniably complex, with limited resources and huge expanses adding to the challenge. However, through local to global governance, increased community engagement, and science to guide and inform actions, significant advancement can be made to turn the tide on ecological, aesthetic, and economic damage resulting from marine litter.

\section{LITERATURE CITED}

Abrams R (2015) Fighting pollution from microbeads used in soaps and creams. The New York Times, 22 May

Beat the Microbead (2015). http://www.beatthemicrobead.org/en/ (accessed 1 Nov 2015) 
Chen CL (2015) Regulation and management of marine litter. In: Bergmann M, Gutow L, Klages M (eds) Marine anthropogenic litter. Springer International Publishing, Cham, Heidelberg, New York, Dordrecht, London

Cho D-O (2009) The incentive program for fishermen to collect marine debris in Korea. Marine Pollution Bulletin 58:415-417

Department of the Environment (2015) Marine debris. https://www.environment. gov.au/marine/marine-pollution/marine-debris (accessed 1 Nov 2015)

Derraik JGB (2002) The pollution of the marine environment by plastic debris: a review. Marine Pollution Bulletin 44:842-852

do Sul I, Costa MF (2014) The present and future of microplastic pollution in the marine environment. Environmental Pollution 185:352-364

Duckett PE, Repaci V (2015) Marine plastic pollution: using community science to address a global problem. Marine and Freshwater Research 66:665-673

Dugdale J (2015) The ocean cleanup plan so crazy it just might work. http://www.outsideonline.com/1999216/ocean-doubt (accessed 1 Nov 2015)

Ecojustice (2015) Ecojustice applauds federal government's plan to ban microbeads. http://www.ecojustice.ca/pressrelease/ecojusticeapplauds federalgovernmentsplantobanmicrobeads/ (accessed 1 Nov 2015)

Fredriksson PG, Millimet DL (2002) Is there a 'California effect' in US environmental policymaking? Regional Science and Urban Economics 32:737-764

Gall SC, Thompson RC (2015) The impact of debris on marine life. Marine Pollution Bulletin 92:170-179

GhostNets Australia (2015) Ghost Nets Australia. http://www.ghostnets.com.au/ (accessed 1 Nov 2015)

Gjølberg M (2009) The origin of corporate social responsibility: global forces or national legacies? Socio-Economic Review 7:605-637

Gold M, Mika K, Horowitz C, Herzog M, Leitner L (2013) Stemming the tide of plastic marine litter: a global action agenda. Pritzker Policy Brief 5:1-30

Haas PM (1992) Introduction: epistemic communities and international policy coordination. International Organization 46:1-36

Hardesty BD, Wilcox C, Lawson TJ, Lansdell M, van der Velde T (2014) Understanding the effects of marine debris on wildlife. A final report for Earthwatch Australia. http://www.csiro.au/Organisation-Structure/ Flagships/Wealth-from-Oceans-Flagship/marine-debris.aspx (accessed October 2015)

Howlett M, How YP, del Rio P (2015) The parameters of policy portfolios: verticality and horizontality in design spaces and their consequences for policy mix formulation. Environment and Planning C: Government and Policy 33:1233-1245

Hu N-TA (2012) Integrated oceans policymaking: an ongoing process or a forgotten concept? Coastal Management 40:107-118

Jambeck JR, Geyer R, Wilcox C, Siegler TR, Perryman M, Andrady A, Narayan $\mathrm{R}$, Law KL (2015) Plastic waste inputs from land into the ocean. Science 347:768-771

Jambeck JR, Johnsen K (2015) Citizen-based litter and marine debris data collection and mapping. Computing in Science \& Engineering 17:20-26

Jay S, Flannery W, Vince J, Liu W, Xue J, Matczak M, et al. (2013) International progress in marine spatial planning. In: Chircop A, Coffen-Smout S (eds) Ocean yearbook. Vol 27. Martinus Nijhoff Publishers, Leiden, Netherlands/Boston, Massachusetts

Kaiser J (2010) The dirt on ocean garbage patches. Science 328:1506

Marine Litter Solutions (2014) Marine litter solutions joint declaration. http://www.marinelittersolutions.com/who-we-are/joint-declaration.aspx (accessed 1 Nov 2015)

Masura J, Baker J, Foster G, Arthur C (2015) Laboratory methods for the analysis of microplastics in the marine environment: recommendations for quantifying synthetic particles in waters and sediments. NOAA Technical Memorandum NOS-OR\&R-48

McIlgorm A, Campbell HF, Rule MJ (2011) The economic cost and control of marine debris damage in the Asia-Pacific region. Ocean and Coastal Management 54:643-651

Morrison J (2014) The social license. How to keep your organization legitimate. Palgrave Macmillan, Basingstoke, United Kingdom
Newman S, Watkins E, Farmer A, ten Brink P, Schweitzer J-P (2015) The economics of marine litter. In: Bergmann M, Gutow L, Klages M (eds) Marine anthropogenic litter. Springer International Publishing http://link.springer.com/book/10.1007\%2F978-3-319-16510-3

Nollkaemper A (1994) Land-based discharges of marine debris: from local to global regulation. Marine Pollution Bulletin 28:649-652

Nursey-Bray MJ, Vince J, Scott M, Hayward M, O’Toole K, Smith T, Harvey N, Clarke B (2014) Science into policy? Discourse, coastal management and knowledge. Environmental Science and Policy 38:107-119

Opfer S, Arthur C, Lippiatt S (2012) NOAA Marine Debris Shoreline Survey Field Guide. US National Oceanic and Atmospheric Administration Marine Debris Program, NOAA, USA https://marinedebris.noaa.gov/sites/ default/files/ShorelineFieldGuide2012.pdf

Palassis S (2011) Marine pollution and environmental law. In: Baird R, Rothwell D (eds) Australian coastal and marine law. The Federation Press, Annandale, Australia

Perkins R, Neumayer E (2012) Does the 'California effect' operate across borders? Trading-and investing-up in automobile emission standards. Journal of European Public Policy 19:217-237

Rayner J, Howlett M (2009) Conclusion: governance arrangements and policy capacity for policy integration. Policy and Society 28:99-109

Rochman CM, Hoh E, Hentschel BT, Kaye S (2012) Long-term field measurement of sorption of organic contaminants to five types of plastic pellets: implications for plastic marine debris. Environmental Science and Technology 47:1646-1654

Rochman CM, Browne MA, Underwood AJ, van Franeker JA, Thompson RC, Amaral-Zettler LA (2015) The ecological impacts of marine debris: unravelling the demonstrated evidence from what is perceived. Ecology 97:302-312

Secretariat of the Convention on Biological Diversity and the Scientific and Technical Advisory Panel_GEF (2012) Impacts of marine debris on biodiversity: current status and potential solutions. Montreal Technical Series No. 67, pages 61

STAP (2011) Marine debris as a global environmental problem: introducing a solutions based framework focused on plastic. A STAP Information Document. Global Environment Facility, Washington, D.C.

The Ocean Cleanup (2015) The ocean clean up. http://www.theoceancleanup.com (accessed 1 Nov 2015)

Thompson RC, Moore CJ, vom Saal FS, Swan SH (2009) Plastics, the environment and human health: current consensus and future trends. Philosophical Transactions of the Royal Society B 364:2153-2166

Titmus AJ, Hyrenbach KD (2011) Habitat associations of floating debris and marine birds in the North East Pacific Ocean at coarse and mesospatial scales. Marine Pollution Bulletin 62:2496-2506

Toloken, S (2014) Science should drive marine litter action. Plastic News, 12 November. http://www.plasticsnews.com/article/20141112/OPINION01/ 141119975/science-should-drive-marine-litter-action (accessed $10 \mathrm{Apr}$ 2016)

Underdal A (1980) Integrated marine policy: What? Why? How? Marine Policy 4:159-169

UNEP (2009a) Guidelines on survey and monitoring of marine litter. United Nations Environment Programme, Nairobi, Kenya

UNEP (2009b) Marine litter a global challenge. United Nations Environment Programme, Nairobi, Kenya

UNEP (2009c) Guidelines on the use of market-based and economic instruments to address the problem of marine litter. United Nations Environment Programme, Nairobi, Kenya

UNEP (2012) The honolulu strategy: a global framework for prevention and management of marine debris. http://www.unep.org/gpa/ documents/publications/honolulustrategy.pdf (accessed 12 Nov 2015)

van Sebille E, Wilcox C, Lebreton L, Maximenko N, Hardesty BD, van Franeker JA, Eriksen M, Siegel D, Galgani F, Law KL (2015) A global inventory of small floating plastic debris. Environmental Research Letters 10:124006

Vince J (2015) Integrated policy approaches and policy failure: the case of Australia's Oceans Policy. Policy Sciences 48:159-180 
Wilcox C, Hardesty BD, Sharples R, Griffin DA, Lawson TJ, Gunn R (2013) Ghostnet impacts on globally threatened turtles, a spatial risk analysis for northern Australia. Conservation Letters 6:247-254

Wilcox C, Heathcote G, Goldberg J, Gunn R, Peel D, Hardesty BD (2014) Understanding the sources and effects of abandoned, lost and discarded fishing gear on marine turtles in northern Australia. Conservation Biology 29:198-206

Wilcox C, Mallos N, Leonard GH, Rodriguez A, Hardesty BD (2016) Estimating the consequences of marine litter on seabirds, turtles and marine mammals using expert elicitation. Marine Policy 65:107-114

Received: 29 February, 2016; First decision: 13 March, 2016; Revised: 20 April, 2016; Accepted: 21 April, 2016 